\title{
Miscellaneous Objects
}

\author{
Elizabeth Minor
}

$1 \quad$ Object Types

The miscellaneous objects from Naga ed-Deir cemeteries N 2000 and N 2500 help shed light on daily life and personal adornment. Cosmetic equipment, such as mirrors, were used in the afterlife to continue to ensure the beauty of the deceased. Headrests were set in the grave to add comfort to their final resting place. Other items - especially tools like a balance scale, grinding stone, hoe, and needle-offer small glimpses of quotidian activities. A small corpus of Coptic objects demonstrates the reuse of ancient graves over time.

\section{Balance scale, copper}

N 2048 PAHMA 6-14345, PAHMA 6-14346

First catalogued as a fragmented copper vessel and bent wire, this balance scale has one almost complete basket and a second basket that is about one-quarter preserved. One thick gauge copper wire fragment is bent over itself and has trace impressions of thread or twine wrapped around one end of it. One basket is almost complete, although broken and reconstructed after excavation. The shallow concave circle has two piercings still visible at about a quarter turn from each other. The other two piercings are hidden under thick corrosion products. The other basket is about one-quarter preserved, with another small fragment of rim. The larger fragment also has a piercing at the rim still visible. These scale baskets are from the same tomb as the bent wire (PAHMA 6-14345), which means that wire is likely its balance beam. There are also faint traces of fiber preserved in one area of rim of the more complete basket, perhaps the remnants of the stringing.

Balance scales are known in Egypt as early as the Predynastic Period (Petruso 1981, 44) and played a key role in economic administration (Petrie 1926). As grave N 2048 had both First Intermediate to Middle Kingdom material and Coptic material, the balance scale could originate in either of those periods.

Bottles, glass (Fig. 9.1)

$\mathrm{N} 2016$ ? MFA 47.1684

$\mathrm{N} 2636 \quad$ MFA 47.1686

$\mathrm{N}_{3747,} \mathrm{~F}_{4} \quad$ MFA 47.1685

(C) ELIZABETH MINOR, 2021 | DOI:10.1163/9789004396906_011

This is an open access chapter distributed under the terms of the CC BY-NC-ND 4.9licensen Minor - 9789004396906 
The three glass bottles from Naga ed-Deir cemeteries N 2000 and N 2500 are of general types known from late Roman and early Byzantine times. Square bottles without indentations and with handles were more common in western regions of the Roman Empire, and were most prevalent in first century and continued through late second century (Whitehouse 2004, 163-164; Cool and
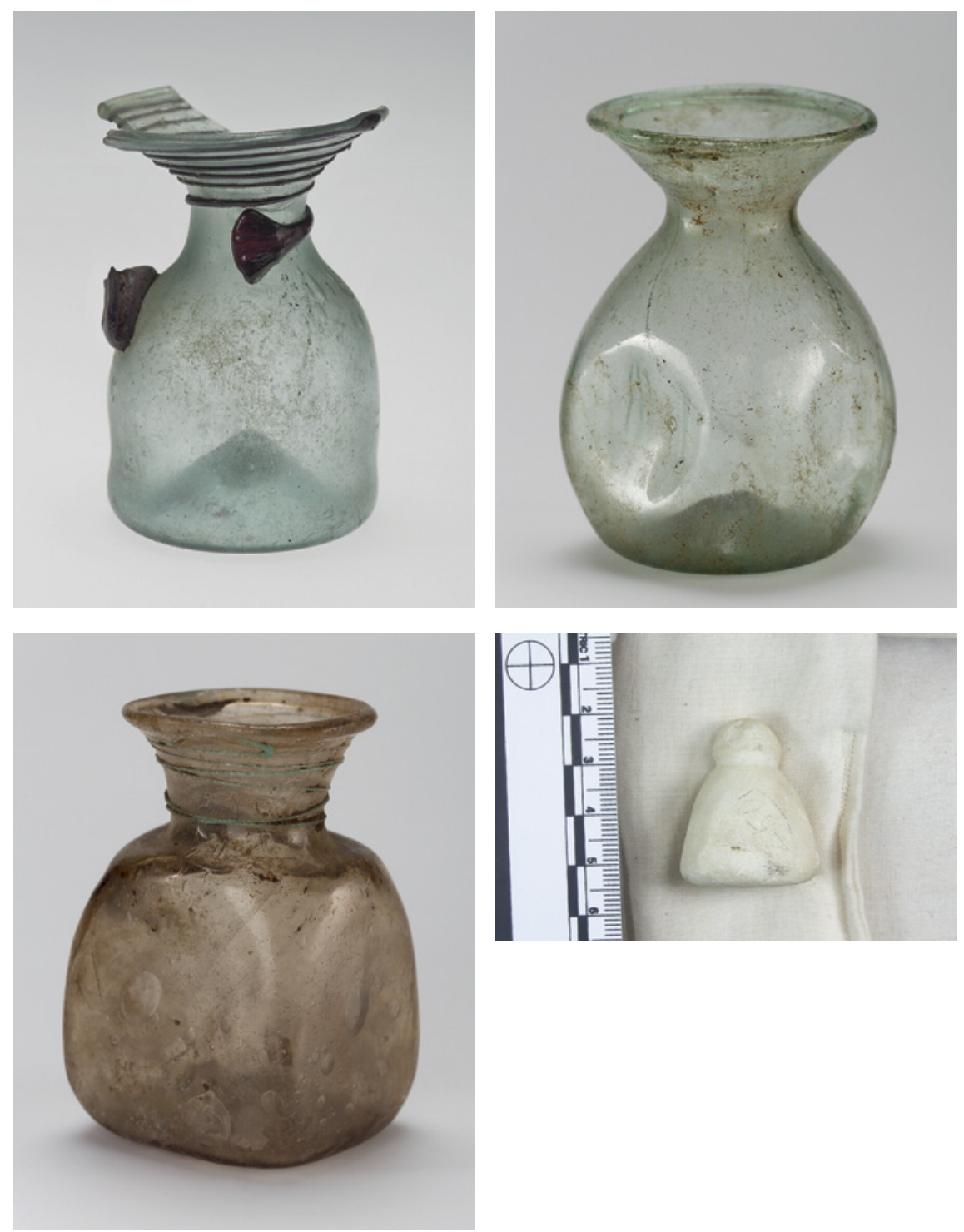

FIGURE 9.1A-D Glass bottles MFA 47.1684 (N 2016), MFA 47.1685 (N 3747, F4), MFA 47.1686 (N 2636). Game piece 6-12501 (N 2501) 
Price 1995, 179-185) The pinched square profile found in these Naga ed-Deir examples is more similar to an example from an otherwise unknown Egyptian context (Whitehouse 1997, 182, no. 321, 356, no. 321). Museum records do not list a findspot at Naga ed-Deir for object MFA 47.1684. It may have been the glass bottle found in $\mathrm{N} 2016$.

Fragments, glass

N 2048 PAHMA 6-14347

A dark brown curved fragment of glass could be part of another bottle, but is too fragmentary for reconstruction. Due to the presence of Coptic blown-glass vessels, this is most likely from the same period of use of the cemeteries and intrusive into the grave.

Game piece (Fig. 9.1)

N $2501 \quad$ PAHMA 6-12501

This single draughtsman once belonged to a set of senet game pieces and is a relatively squat, large, and heavy example. Before the New Kingdom, senet games were included in tombs in physical form and depicted in wall paintings as part of daily life scenes of enjoyment in the afterlife (Piccione 1980, 57; Kendall 1982, 263-264). No fragments of the rest of the set nor of the game board were noted by the excavators.

\section{Gold flakes}

N 2031 PAHMA 6-14310

This thin gold foil has a reddish tinge over $6 \circ \%$ of surface. The fragments are too small and deformed to identify the original form. The excavators noted decayed wood and suggested this gold foil is the remains of a gilded object. Found near the neck of the deceased, this could have been a jewelry element, amulet, or displaced furniture/box element.

\section{Grinding stone}

N 2093 PAHMA 6-14414

The roughly shield-shaped groundstone has a flat side with a deep central well, although that side has broken off into three small flakes. The other side is more rounded, worked into a pillowed shape, with a flattened middle section. The groundstone is sized and shaped to be held comfortably in the hand. Due to the fragmented grinding side, no residue remains to help identify what substance was processed with this implement. This utilitarian palette is of a type found in Middle Kingdom tombs (Stevenson 2009, 6). 


\section{Handle, hoe}

N 2606 PAHMA 6-12505

A well-worn wooden agricultural hoe was originally complete with a blade and connecting rope, which have been missing since 1983. The remaining handle is smoothed from frequent use, with a hole for attaching the blade, and a tang midway along the shaft for holding the tension-bearing rope in place. This hoe was used in life and was possibly included in the tomb to promote agricultural fertility in the afterlife rather than relying on a magical substitution such as a tomb model or shabti.

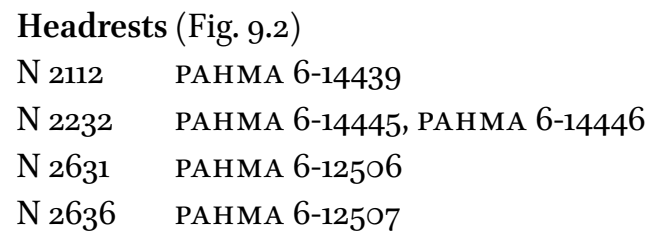

Elements of five wooden headrests were recovered from four tombs in cemeteries $\mathrm{N} 2000$ and $\mathrm{N} 2500$ at Naga ed-Deir. An important object for ensuring comfort during life and for eternity, several of the headrests have wear patterns showing that they had seen regular use before interment. Two headrests are of the typical form with a flat base, stem, and curved platform to support the

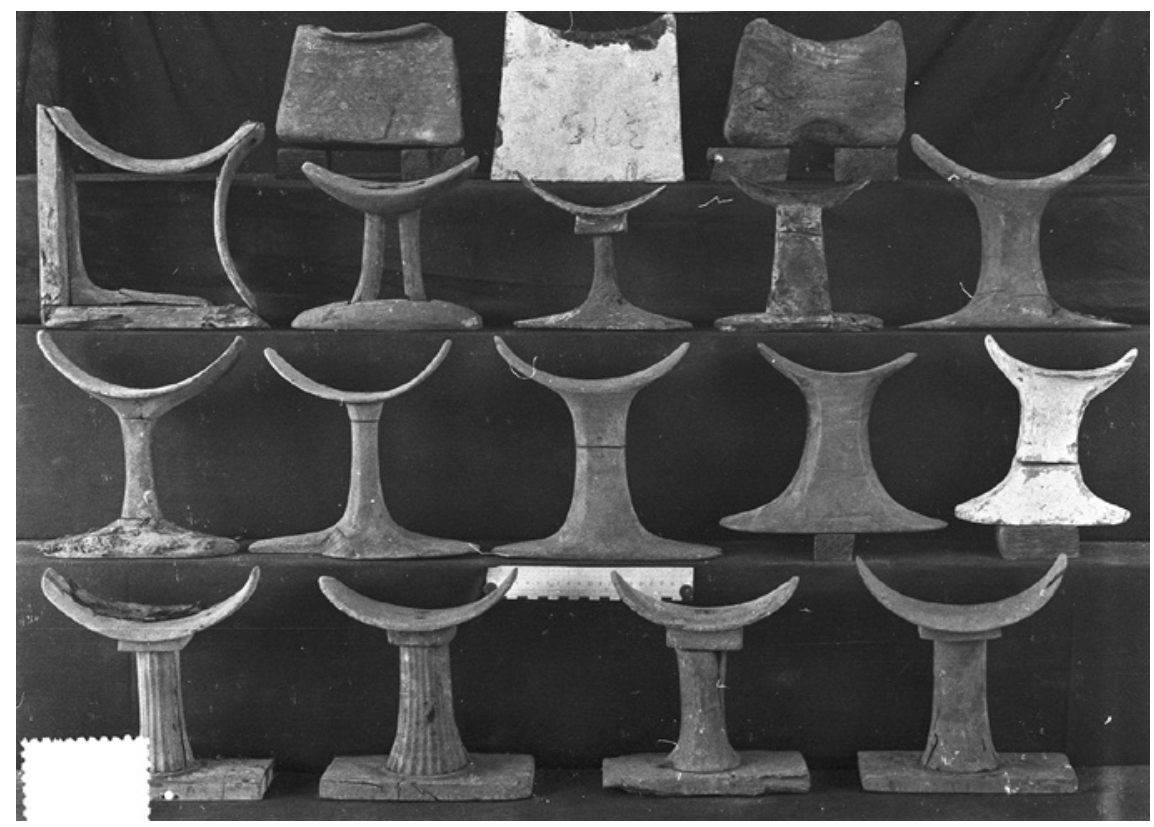

FIGURE 9.2 Headrest (2nd row): \#1=6-14446 (N 2232) (NED-B-7148) 
head (PAH MA 6-14439, PAHMA 6-12506). One block headrest is more utilitarian than decorative (PAHMA 6-12507). One fragmentary headrest takes an unusual form (PAHMA 6-14445, PAHMA 6-14446), with one braced L-shape component, with a second L-shaped element made of two curved platforms attached to it. This unique piece of woodworking could offer a choice of two different platforms on which to lay one's head, but is not a double headrest meant for use by a couple as is found in West and South African ethnographic examples (Nettleton 2007, figs. 154, 167, 412, 413).

Due to the vagaries of organic preservation at Naga ed-Deir, these fragmentary headrests are likely only a small selection of what may have originally been contained in the graves of cemeteries N 2000 and N 2500. As a standard element of funerary equipment, headrests were meant to magically protect the head of the deceased (Fischer 1979, 688-689). In order to perform this protection, headrests were listed in Coffin Texts spells (Fischer 1979, 688-689), depicted on painted coffins (Freed 2009, 143), and set within the grave. The two stemmed headrests have octagonal stems, which is slightly more common in the New Kingdom than Middle Kingdom, but have roughly equal lengths for the base and top platform which fits with the Middle Kingdom corpus (Fischer 1979, 687-689).

Jewelry (Fig. 9.3)

\section{Bracelets}

N 3747, F16 MFA Eg.Inv.1541

\section{Earrings}

N 3747, F17 MFA Eg.Inv.1544

\section{Earrings (Coins)}

Not given MFA Eg.Inv.1542

Not given MFA Eg.Inv.1545

Two sets of heavy metal bracelets were made for a child. One set has a bezel with dots in the shape of the cross, and the other set has geometric decoration incised into the metal. One earring is made from pressed bronze sheeting, with a lobed rosette suspending a ball. Three earrings were made from pierced Byzantine copper coins. The corrosion has obscured most of the coin imprints. The most visible marking on the coins is the large $\mathrm{M}$ on the reverse, denoting the 40 nummi follis coin first minted by Anastasius I in $498 \mathrm{CE}$ and retired by Theophilus by 829 CE (Grierson 1999, 17-20). 


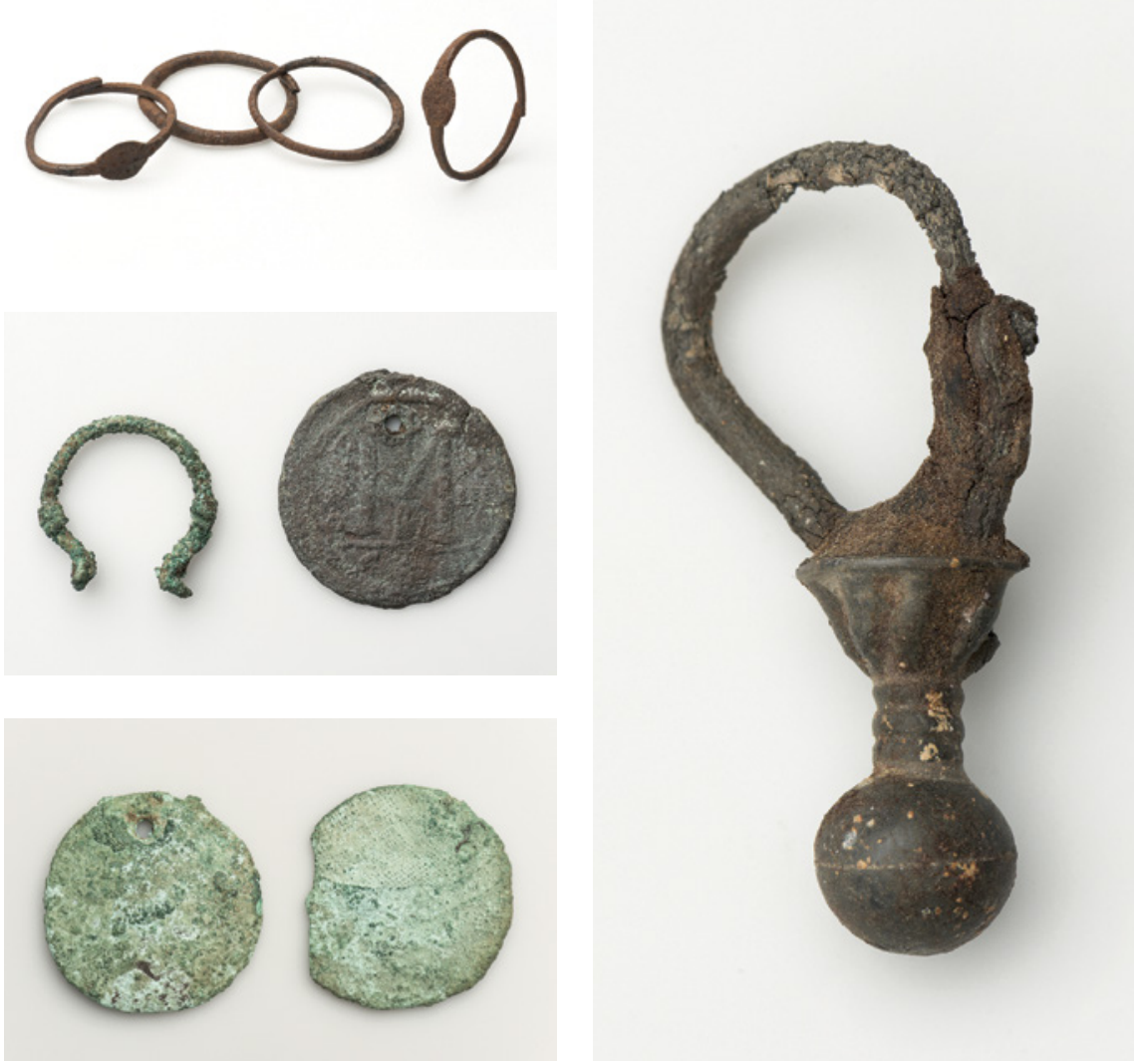

FIGURE 9.3A-D Jewelry/coins MFA Eg.Inv.1541 (N 3747, F16), MFA Eg.Inv.1542, MFA Eg.Inv.1544 (N 3747, F17), MFA Eg.Inv.1545

Mirrors (Fig. 9.4)

N 2071 PAHMA 6-14366

N 2075 PAHMA 6-14393, PAHMA 6-14394, PAHMA 6-14395

N 2091 PAHMA 6-14409

N 2103 PAHMA 6-14434

N 2105 PAHMA 6-14436

N 2447 PAHMA 6-14537

N 2449 PAHMA 6-14538

The mirrors from Naga ed-Deir $\mathrm{N} 2000$ and $\mathrm{N} 2500$ have a consistent form of a disc that is slightly wider in proportion and has a long tang for attachment to the handle. No handles are preserved, which may suggest that they all were 


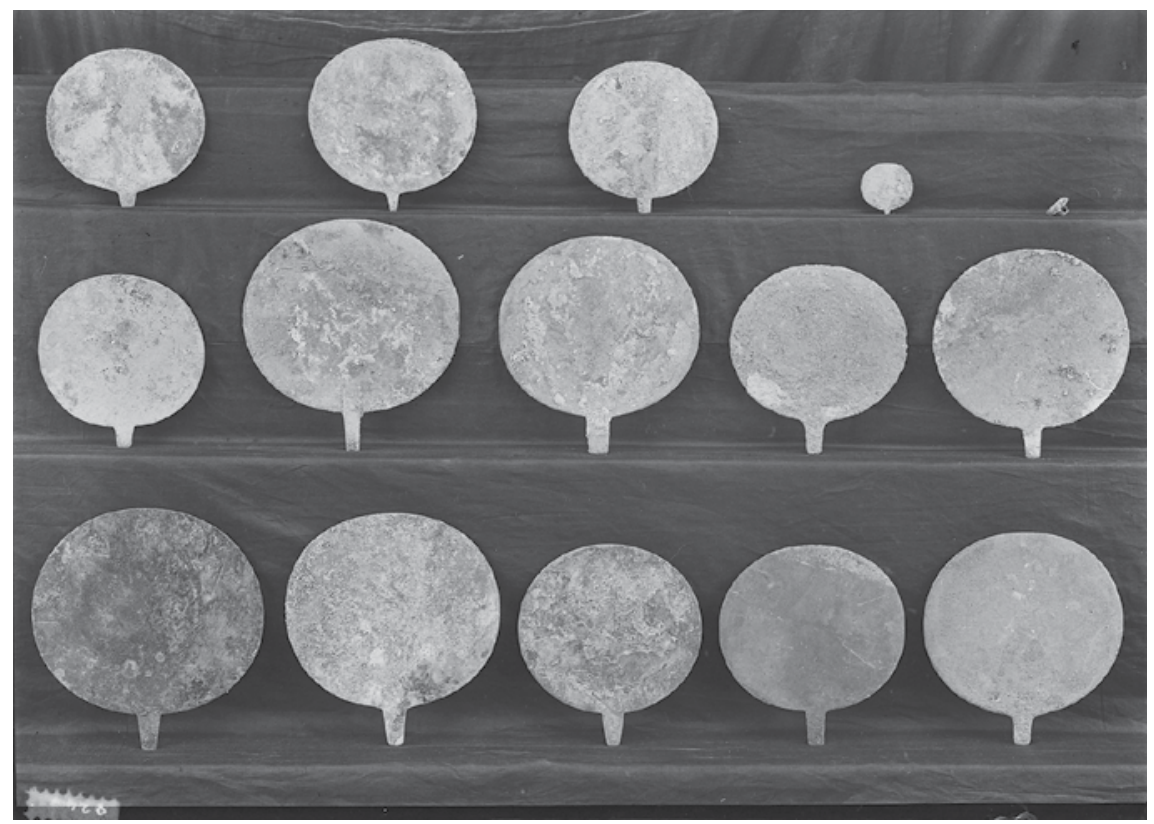

FIGURE 9.4 Mirrors (Top row): \#1=6-14395 [?] (N 2075), \#2=6-14393 [?] (N 2075), \#3=6-14394 [?] (N 2075), \#4=6-14366 (N 2071); (2nd row): \#2=6-14436 (N 2105), \#3=6-14434 (N 2103), \#4=6-14537 (N 2447), \#5=6-14538 (N 2449) (NED-B-8244)

made of wood rather than ivory or another material that would have better preservation. Unfortunately, without the handle it is difficult to put the mirrors within a decorative typology (Lilyquist 1979, 1982, 2007). One mirror has a slightly unusual tang that is attached by rivets, which may be a manufacturing technique local to Naga ed-Deir as a comparable example was found in the Middle Kingdom tomb 435B (MFA 21.10559).

\section{Needle}

$\mathrm{N} 2075$ PAHMA 6-14388

This ubiquitous piece of sewing implement has been found in a long range of ancient Egyptian contexts (Vogelsang-Eastwood 1999, 282), and therefore could be from First Intermediate Period to Middle Kingdom deposits or from Coptic ones as well. This needle has a bend about $1 / 3$ of length from tip. The shaft of the needle is round in cross section. The eye of the needle is a precise tiny circle on one side, and is broken or corroded into a larger slit on the other side. The point of the needle is well formed and sharp. 


\section{Wire, rectangle}

N 2075 PAHMA 6-14387

This copper alloy object is a rectangle, possibly made by casting, with four sets of incised double lines and one deeper groove in the middle of one side. This may be a product of more recent manufacture, such as a buckle.

\section{Miscellaneous Objects Catalogue}

Explanation of the Catalogue of Miscellaneous Objects:

The finds' description of context below is taken from the Catalogue of Tombs. The photograph numbers reflect the original excavator's numbering system.

Material: Glass, copper alloy, iron(?), gold, sandstone(?), travertine, wood, linen.

Measurements: Diameter, height, height with tang, length, thickness, width.

Color: Reddish-purple, reddish-brown, yellow, blue, blue-green, green, copper, bronze, gold, off-white, grey, brown, black, clear.

N 2016 (TC) Map D4; photos A 8267, B 8251, C 8193, C 8464, C 8465 (Fig. 9.1)

In filling at top of pit, small glass bottle (MFA 47.1684?), piece of a large dish with Coptic inscription scratched on it, and broken pottery.

(1) MFA 47.1684 Glass bottle

Material: Glass.

Measurements: $\mathrm{H}_{5.3} \mathrm{~cm} \times \mathrm{W}_{3.9} \mathrm{~cm}$.

Color: Clear and red.

Glass bottle, round cross-section with a deep concave bottom and flared rim. Bluish-clear glass body with dark opaque reddish-black applied spiral decoration on the rim and broken remnant of a handle on the shoulder.

N 2031 (TC) Map E3; photo C o983, C 7178, C 7179

a. By neck, quantity of gold foil (PAHMA 6-14310) had been upon something made of wood.

(1) PAHMA 6-14310 Gold, fragments

Material: Gold.

Measurements: Largest fragment: $5.5 \mathrm{~cm} \times 4.0 \mathrm{~cm}$; Thickness: $0.02 \mathrm{~cm}$.

Color: Reddish tinged gold. 
N 2048 (TC) Map B3; photo C 8285

[ed.: According to Hearst Museum records, PAHMA 6-14345, PAHMA 6-14346, PAH MA 6-14347 are from this burial.]

(1) PAHMA 6-14345 Wire, bent (Part of Balance scale)

Material: Copper alloy.

Measurements: L $0.5 \mathrm{~cm}$ (bent), $9.2 \mathrm{~cm}($ total $) \times \mathrm{T} 0.2 \mathrm{~cm}$.

Color: Corrosion products are green, blue, and yellow.

Thick gauge copper or copper alloy wire that is bent over on itself. One end of the wire has marks as if thread or twine were wrapped around it and have been preserved in corrosion products.

(2) PAH MA 6-14346 Balance Scale

Material: Copper alloy.

Measurements: Complete basket: D $4.0 \mathrm{~cm} \times \mathrm{T} 0.1 \mathrm{~cm}$.

Fragment 1: $3.3 \mathrm{~cm} \times 2.4 \mathrm{~cm}$; Fragment 2: $2.8 \mathrm{~cm} \times 1.1 \mathrm{~cm}$.

Color: Corrosion products are green, blue, and yellow.

These scale baskets are from the same tomb as the bent wire (PAHMA 6-14345), which means that wire is likely its balance beam.

(3) PAHMA 6-14347 Glass fragment

Material: Glass.

Measurements: L $2.8 \mathrm{~cm} \times \mathrm{W} 3.6 \mathrm{~cm} \times \mathrm{T} 0.3 \mathrm{~cm}$.

Color: Dark brown.

Triangular fragment of dark brown glass. Inner surface is matte from weathering, breaks are fresh looking. The color is concentrated and dark. Without light coming through it, the glass looks black. Some small bubbles inside the glass show the direction of the turning/blowing of the vessel. One stripe of abrasions on the outside show where the glass was held during working and blowing the glass. Another stripe of rippled/bubbles are above. The color, translucence, and manner of blowing the glass make it unlikely that this is from earlier than the Roman or Coptic period.

N 2071 (TC) Map B4; type rock-cut chamber with sloping entrance; photos A 8267, A 8268, B 8250, C 8074, C 8194, C 8285, C 8567 (Fig. 9.4)

[ed.: According to Hearst Museum records, PAH MA 6-14366 (mirror) is labeled as potentially coming from this burial.] 
(1) РАнма 6-14366 Mirror

Material: Copper alloy.

Measurements: $\mathrm{H} 4.3 \mathrm{~cm} \times \mathrm{W} 4.7 \mathrm{~cm} \times \mathrm{T}$ 0.1 cm; Height with tang: $4.7 \mathrm{~cm}$.

Color: Corrosion products are blue-green, green, and yellow.

Ovoid mirror, copper alloy, with significant corrosion products. Very short tang, possibly broken off in antiquity (has corrosion on end of it).

N 2075 (TC) Map A4; type vi d; photo B 8248, C 8074, C 8194, C 8285 (Fig. 9.4) [ed.: According to Hearst Museum records, PAHMA 6-14387, PAHMA 6-14388, PAHMA 6-14393, PAHMA 6-14394, and PAHMA 6-14395 are from this burial.]

(1) РАнма 6-14387 Wire, rectangle

Material: Copper alloy.

Measurements: L $3.1 \mathrm{~cm} \times \mathrm{W} 2.0 \mathrm{~cm} \times \mathrm{H} 0.3 \mathrm{~cm}$.

Color: Corrosion products are light green, yellow, black, and deep blue-green.

Rectangle made of cast metal, one long side of the rectangle is thicker and has four sets of incised double lines, with one deeper groove in the middle. The deeper groove in the middle is likely where the tang of a buckle would sit, although that piece is now missing. The metal is likely copper alloy and is in a solid state of preservation. Seems more likely to be of more recent manufacture, perhaps a belt buckle from modern use.

(2) PAнма 6-14388 Needle, bent

Material: Copper alloy.

Measurements: L $8.1 \mathrm{~cm} \times \mathrm{T}$ 0.1-0.2 cm.

Color: Brown.

Bent about one third of length from tip of needle.

(3) PAнма 6-14393 Mirror

Material: Copper alloy, linen.

Measurements: H 14.5 cm $\times$ W 15.3 cm $\times$ T $0.2 \mathrm{~cm}$; Height with tang: $15.7 \mathrm{~cm}$.

Color: Corrosion products are blue-green, green, and yellow.

Ovoid mirror, copper alloy, corrosion product covers $100 \%$ of surface, mostly thin powdery blue green color, medium thick yellow, and front side has significant remains of linen textile preserved in blue-green corrosion product ( $10 \%$ of surface of the disc). Pattern of textile in corrosion product over about 
$25 \%$ of front of disc and $25 \%$ of back of disc. Preserved textile is S-twist, relatively coarse weave. About 18 threads per centimeter. Tang is trapezoidal and complete.

(4) PAHMA 6-14394 Mirror

Material: Copper alloy.

Measurements: $\mathrm{H} 12.8 \mathrm{~cm} \times \mathrm{W} 14.0 \mathrm{~cm} \times \mathrm{T} 0.1 \mathrm{~cm}$; Height with tang: $14.3 \mathrm{~cm}$.

Color: Corrosion products are blue-green, gold, and brown.

Ovoid mirror, copper alloy with deep reddish brown base color. Significant corrosion on $10 \%$ of upper surface, less on lower surface. Corrosion is thick and crystalline, gold and brown in color with ring of blue-green powdery corrosion. Tang is short and looks like it was broken in antiquity.

(5) PAHMA 6-14395 Mirror

Material: Copper alloy.

Measurements: H $17.8 \mathrm{~cm} \times$ W $19.4 \mathrm{~cm} \times \mathrm{T}$ 0.1-0.2 cm; Height with tang: $21.4 \mathrm{~cm}$. Color: Copper

Copper alloy ovoid mirror, no corrosion products left after cleaning. Possible pattern of textile that could have been adhered with corrosion, but could also be bubbles or impurities in copper alloy.

N 2091 (TC) Map C5 (red)

[ed.: According to Hearst Museum records, PAH MA 6-14409 is from this burial.]

(1) PAHMA 6-14409 Mirror

Material: Copper alloy.

Measurements: $\mathrm{H} 12.3 \mathrm{~cm} \times \mathrm{W} 13.3 \mathrm{~cm} \times \mathrm{T} 0.1 \mathrm{~cm}$; Height with tang: $12 \mathrm{~cm}$.

Color: Corrosion products are blue-green, black, and yellow.

Ovoid mirror, copper alloy with corrosion products over $100 \%$ of surface on front and back, light colored in general, yellow, powdery blue-green, and some black. Impression of textile on one side. Tang looks complete.

N 2093 (тC) Map C5; photo B 7129, B 7144

In large chamber, granite paint grinder and pebble (PAHMA 6-14414).

(1) PAHMA 6-14414 Grindstone/Metate/Quern

Material: Sandstone (?). 
Measurements: $\mathrm{H} 1.7 \mathrm{~cm} \times \mathrm{L} 11.9 \mathrm{~cm} \times \mathrm{W} 8.1 \mathrm{~cm}$.

Color: Dark grey.

Pebble noted in excavation records is no longer present. The dark gray stone has a homogenous granular texture/sandy grain, fine crystals, and no inclusions. It is probably dark sandstone, and definitely not slate or schist. The tomb number ( $\mathrm{N}$ 2093) is written on it twice in blue pencil. A possible parallel to this object is BM EA 5547 .

N 2103 (TC) Map C4; type vi b; photo C 8074, C 8194 (Fig. 9.4)

[ed.: According to Hearst Museum records, PAHMA 6-14434 is from this burial.]

(1) PAHMA 6-14434 Mirror

Material: Copper alloy.

Measurements: $\mathrm{H} 16.6 \mathrm{~cm} \times \mathrm{W}_{18.3} \mathrm{~cm} \times \mathrm{T} 0.3-0.5 \mathrm{~cm}$; Height with tang: $20.2 \mathrm{~cm}$. Color: Corrosion products are green.

Ovoid mirror, copper alloy, corrosion product covers $100 \%$ of surface. Very thick dark green corrosion product, in about $1 \%$ of disc linen textile is visible, immersed in corrosion. One exposed thread is well preserved, S-twist. More textile may be preserved under the surface of the very thick corrosion product. Two small flakes on the other side expose shiny copper alloy. Thicker disc and larger shape makes this much heavier than previous examples. The tang is wide, thick, and elongated. A small ridge runs around the middle, perhaps from attachment to handle. On the back side, a horizontal texture may be wood grain or even perhaps wrapped string.

$\mathrm{N}_{2105}$ (TC) Map D4 (Fig. 9.4)

On underside of mirror, remains of cloth (РAHMA 6-14436).

(1) PAHMA 6-14436 Mirror

Material: Copper alloy.

Measurements: $\mathrm{H} 17.5 \mathrm{~cm} \times \mathrm{W} 19.7 \mathrm{~cm} \times \mathrm{T}$ 0.1-0.2 cm; Height with tang: $21.2 \mathrm{~cm}$. Tang: L $5.7 \mathrm{~cm} \times \mathrm{W} 1.4 \mathrm{~cm} \times \mathrm{T}$ o.6 cm; Diameter, rivets: $0.4 \mathrm{~cm}$.

Color: Corrosion products are blue-green, mostly copper.

Ovoid copper alloy mirror, very little corrosion except near tang, powdered blue-green corrosion product. Likely that it was cleaned with electrolysis. Textile pattern present on top third of one side of disc, but remnants were removed through electrolysis. The tang has unusual attachment. Two rectangular 
strips of copper alloy were sandwiched around the disc and hammered together below the disc. Two rivets run through the tang sections and disc to hold it together. For a comparable example, see MFA 21.10559 (www.mfa.org/ collections/object/mirror-144674)

$\mathrm{N} 2112$ (TC) Map D3

Wooden headrest (i) (PAHMA 6-14439).

(1) PAHMA 6-14439 Headrest

Material: Wood, linen.

Measurements: Top section: $\mathrm{H} 7.4 \mathrm{~cm} \times \mathrm{L} 20.3 \mathrm{~cm} \times \mathrm{W} 6.0 \mathrm{~cm}$.

Base section: $\mathrm{H} 14.1 \mathrm{~cm} \times \mathrm{L} 22.1 \mathrm{~cm} \times \mathrm{W} 7.6 \mathrm{~cm}$.

Cross-section of stem: $\mathrm{L} 7.6 \mathrm{~cm} \times \mathrm{W} 4.4 \mathrm{~cm}$.

Color: Brown.

Complete headrest in three pieces, two of which are still attached by pegs. The top section is carved to make a strong lunate curve, with a small lip overhang on the long sides. The top section pinches down into the stem, which is octagonal but is an elongated rectangle with trimmed edges (very similar to the cross-section of PAHMA 6-12506). The grain of the wood runs in the lengthwise direction of the headrest. Two roughly square holes are cut into the base of the top section. A small piece of linen (c. $3 \mathrm{~mm}$ square) is adhered inside one hole.

The stem of the headset is the second piece. The grain runs vertically and the cross-section matches the octagon of the top piece. The two pegs that were carved into the top of the second section are rectangular in cross-section (matching the holes in the bottom of the top section). Linen remnants are adhered on all four sides of one peg and one side of the other peg. The linen may have been used to keep the peg in place during use. The section section is still connected to the base section. The two long, flat rectangular pegs that come down from the middle section can be seen in the holes that go through the base section. No linen remnants are visible in this connection.

The base section follows the octagonal cross-section, then flares out into an elongated oval base. The wood grain once again runs in the lengthwise direction of the base.

N 2232 (TC) Map E4; photos C 7468, C 8589, C 859 o (Fig. 9.2)

Male. Headrest (i) corners pierced with double holes and tied with cord (PAHMA 6-14445, PAHMA 6-14446). a. Extra piece pegged on middle of inside. Rounded. 1 wide at ends, 2 at corner. Wood of main pieces 2 thick, 7 wide, 23 square. 
(1) РАнма 6-14445 Headrest fragment

Material: Wood.

Measurements: $\mathrm{H} 0.9 \mathrm{~cm}(\max ) \times \mathrm{L} 21.5 \mathrm{~cm} \times \mathrm{W} 8.4 \mathrm{~cm}$.

Color: Brown.

Piece of wood that is shaped and carved as if a headrest top, but has two pairs of two holes on edges for attachment to another element(s). Remains of peg in one hole. When set on flattened edge of tip of wooden piece, makes a 9o-degree surface on the back of the other tip.

(2) PAHмA 6-14446 Headrest and/or box fragments

Material: Wood.

Measurements: $\mathrm{L} 12 \mathrm{~cm} \times \mathrm{W} 6.7 \mathrm{~cm}$.

Color: Brown.

Multiple wooden fragments. One L-shaped brace and two rectangular segments with two peg holes on each end are part of a headrest. The two rectangular segments were held in alignment by the angled brace. The other half of the headrest was observed to be made of PAHMA 6-14445 and a matching curved piece, now lost.

N 2447 (TC) Map B4; photo C 8542 (Fig. 9.4)

Adult. Female? Bronze mirror (PAHMA 6-14537), resting on 2 rough stones. Cloth on under side.

(1) РАнма 6-14537 (1) Mirror

Material: Copper alloy.

Measurements: H 14.5 cm $\times$ W 15.9 cm $\times$ T 0.1-0.4 cm; Height with tang: $17.5 \mathrm{~cm}$. Color: Corrosion products are blue-green.

Ovoid copper alloy mirror, corrosion product over $80 \%$ on back (powdery blue-green), on $15 \%$ of front (powdery blue-green), and with textile preserved in corrosion product. Textile pattern extends into top of tang as well.

There are two copper alloy mirrors assigned the Object Number PAHMA 6-14537 in the Phoebe A. Hearst Museum of Anthropology collection. The excavation records only list one mirror from this tomb, leaving the cause of this duplication error unknown.

(2) PАН MA 6-14537 (2) Mirror

Material: Copper alloy. 
Measurements: H 15.6 cm $\times$ W 17.5 cm $\times$ T 0.1-0.2 cm; Height with tang: $17.4 \mathrm{~cm}$. Color: Corrosion products are blue-green.

Ovoid copper alloy mirror, corrosion product over $2 \%$ of disc (flaking bluegreen powdery), flaking edges, one side is shiny from cleaning by electrolysis. This one matches the tomb card description better because it has textile imprints on one side.

N 2449 (TC) Map B4 (Fig. 9.4)

[ed.: According to Hearst Museum records, PAHMA 6-14538 is from this burial.]

(1) PAнма 6-14538 Mirror

Material: Copper alloy.

Measurements: H 16.3 cm $\times$ W $17.7 \mathrm{~cm} \times$ T $0.2 \mathrm{~cm}$; Height with tang: $19.1 \mathrm{~cm}$.

Color: Copper.

Ovoid copper alloy mirror, has been cleaned in the past (electrolysis?), 100\% no corrosion deposits on surface. No traces of textile pattern on surface.

N 2501 (1) Map N/A [ed.: This record is Reisner's note of preliminary work that was done in 1901.] (Fig. 9.1)

Alabaster (ii) (PAHMA 6-12501).

(1) PAнма 6-12501 Game piece/draughtsman

Material: Travertine.

Measurements: $\mathrm{H} 3.5 \mathrm{~cm} \times \mathrm{W} 2.8 \mathrm{~cm}$ (base), $1.4 \mathrm{~cm}$ (knob).

Color: Off-white.

Squat example of a senet conical game piece. Travertine is consistent in light cream color and flat crystals. The ball top is also more squat than typical form, with sharper edge along bottom by neck to conical base. Tomb number (2501) is written on it twice in pencil. Relatively large and heavy for a game piece.

N 26o6 [ed.: No such tomb number exists on the map or in the tomb cards, but according to Hearst Museum records, the following object was found in that tomb.]

(1) PAHмA 6-12505 Hoe handle

Material: Wood. 
Measurements: $\mathrm{H} 4.1 \mathrm{~cm}(\max ) \times \mathrm{L} 48 \mathrm{~cm} \times \mathrm{W} 4.1 \mathrm{~cm}(\max )$.

Color: Light brown.

Hoe handle, long curved section. Rope missing since $2 / 83$. Shape identical to most agricultural tools of this type. Midway along the shaft the point of connection for the rope is a tang that is a seven-sided tear-drop in cross section. The end of the handle is worn from use with a sheen on the wood.

N 2631 (тC; мM) Map E4; photo C 7156

From scattered original contents of burial inside coffin. [ed.: According to Hearst Museum records, PAHMA 6-12506 is from this burial.]

(1) PAHMA 6-12506 Incomplete headrest

Material: Close-grained wood, acacia (?).

Measurements: H 9.7 cm $\times$ L $21.2 \mathrm{~cm} \times \mathrm{W} 8.0 \mathrm{~cm}(\max ), 6.9 \mathrm{~cm}($ stem).

Color: Brown.

Octagonal cross section, rectangular with trimmed edges. Elongated oval flared base. Most likely acacia, with strong grain. Broken close to the stem for top half. Stable condition.

N 2636 (тс; м м) Map D3; photo C 7028, C 8456, C 8457 (Fig. 9.1)

Copt. Female aged approx. 25. By right hand, a small glass bottle (MFA 47.1686). [ed.: According to Hearst Museum records, PAH MA 6-12507 is from this burial.]

(1) MFA 47.1686 Glass bottle

Material: Glass.

Measurements: H $6.7 \mathrm{~cm} \times \mathrm{W} 4.8 \mathrm{~cm} \times \mathrm{T} 4.0 \mathrm{~cm}$.

Color: Reddish-purple with blue-green applied decoration.

Rectangular body with large bubble inclusions. Reddish-purple glass with spiraled blue-green glass decoration at rim. Convex bottom. Reddish-brown residue inside.

(2) PAH MA 6-12507 Block headrest

Material: Wood.

Measurements: $\mathrm{H} 16.4 \mathrm{~cm} \times \mathrm{L} 20.7 \mathrm{~cm} \times \mathrm{W}_{7.2} \mathrm{~cm}$.

Color: Brown.

This block headrest has roughly shaped sides with adze marks visible on the thin vertical sides and many overlapping parallel scratches on one wide side 
(the one that the top slopes down to). The wood looks like acacia. The wood grain runs in the lengthwise direction of the headrest. The center of the tree rings can be seen on the thin vertical section, and the cracks run radially out from the center of the tree rings. The top of the headrest is shaved down and worn from use (with a slight sheen from wear on the edge that the top slopes down to). The curve exposes the tree rings but on the horizontal plane instead of cross-cutting them. The very top of the curve and part of the bottom edge seem slightly separated, have a thicker, spongy texture, and may be close to the bark section of the tree. The tomb number $\mathrm{N}_{2} 636$ is written on the headrest on two different sides.

N 3747 (TC) [ed.: See also N 2640.] Map D3; photos C o212, C o213, C o781, C o814, C 775o, C 7751, C 7752, C 7753, C 7754, C 7755, C 7756, C 8503, C 8504, C 8574 (Figs. 9.1, 9.3)

N 3747, F4 photos C 8451, C 8456, C 8457, C 8472

4. Female aged approx. $25^{-28}$. By head, inside wrappings, a small glass bottle (ii) with an indentation each side and at bottom (MFA 47.1685).

(1) MFA 47.1685 Glass bottle

Material: Glass.

Measurements: $\mathrm{H}_{5.6} \mathrm{~cm} \times \mathrm{W}_{3.7} \mathrm{~cm}$.

Color: Clear.

Clear glass with blue tinge, no applied decoration. Four dimples on each side, not precisely aligned, so the bottle is a pentagon in cross-section. Concave bottom and flared rim. Minimal bubbles in glass and no residue.

$\mathrm{N}_{3747}$, F16 photos $\mathrm{C}_{7787}, \mathrm{C} 8475$

Small child aged approx. 3. On each arm, 2 iron bracelets (i), 2 with (ii) [ed.: i.e., bezel] (MFA Eg.Inv.1541).

(1) MFA Eg.Inv.1541 Bracelets

Material: Iron(?).

Measurements: D $4.1 \mathrm{~cm} \times \mathrm{T} 1.0 \mathrm{~cm}$.

Color: Reddish-brown.

Heavy metal with reddish-brown corrosion. Two pairs of bracelets. One pair has incised herringbone decoration on overlapping points and seven sets of double lines along the rest of the loop. The other pair has a flattened middle area with six dots arranged to make a cross. 


\section{$\mathrm{N} 3747, \mathrm{~F}_{17}$ photo $\mathrm{C} 845^{1}$}

Adult female. By left ear, silver? [bronze] earring (iii) (MFA Eg.Inv.1544). Right one had gone.

(1) MFA Eg.Inv.1544 Earring Material: Bronze or other copper alloy.

Measurements: L $4.1 \mathrm{~cm} \times \mathrm{D} 1.9 \mathrm{~cm}$ (of loop).

Color: Brown.

Drop earring with rosette and ball. Light and hollow bronze sheeting.

N 4511 (TC) Not on map; photos C 8479, C 8571 (Fig. 9.3)

Copt. Small child. Above left shoulder, copper disc, possibly coin, dated 4th year of Justinian (perhaps MFA Eg.Inv.1542 or MFA Eg.Inv.1545?).

(1) or MFA Eg.Inv.1542 Coin earring(?)

Material: Bronze or copper alloy.

Measurements: D $3.9 \mathrm{~cm} \times \mathrm{T} 0.2 \mathrm{~cm}$.

Color: Green and bronze.

Pierced copper coin with curved C-shaped wire. Coin is complete and corroded, only reverse imprint legible is an $\mathrm{M}$ with a cross over it and illegible letters on either side and below (40 nummi Byzantine follis). Obverse has male face with an illegible inscription arched above it.

(2) MFA Eg.Inv.1545 Coin earrings(?)

Material: Bronze or copper alloy.

Measurements: D $4.0 \mathrm{~cm} \times \mathrm{T} 0.2 \mathrm{~cm}$.

Color: Green and bronze.

Two pierced copper coins. One coin is very corroded, has the imprint of fabric, and is not legible. The other coin is complete and corroded. The only imprint legible is an $\mathrm{M}$ with a cross over it (40 nummi Byzantine follis).

\section{Bibliography}

Cool, H. and J. Price. 1995. Roman Vessel Glass from Excavations in Colchester, 1971-1985. Colchester.

Fischer, H. G. 1979. “Kopfstütze." In Lexikon der Ägyptologie 3, edited by W. Helck and E. Otto, cols. 686-693. Wiesbaden. 
Freed, R. E. 2009. The Secrets of Tomb 10A: Egypt 2000 BC. Boston.

Grierson, P. 1999. Byzantine Coinage. Dumbarton Oaks Byzantine Collection Publications. Washington [DC].

Kendall, T. 1982. "Games." In Egypt's Golden Age: The Art of Living in the New Kingdom 1558-1085 B.C., by R. Freed, 263-272. Boston.

Lilyquist, C. 1979. Ancient Egyptian Mirrors from the Earliest Times through the Middle Kingdom. MÄs 27. Munich.

Lilyquist, C. 1982. "Mirrors." In Egypt's Golden Age: The Art of Living in the New Kingdom 1558-1085 B.C., by R. Freed, 184-188. Boston.

Lilyquist, C. 2007. "Reflections on Mirrors." The Archaeology and Art of Ancient Egypt: Essays in Honor of David B. O'Connor, Vol. 2, edited by Z. A. Hawass and J. Richards, 95-109. ASAE 36. Cairo.

Nettleton, A. 2007. African Dream Machines: Style, Identity and Meaning of African Headrests. Johannesburg.

Petrie, W. M. F. 1926. Ancient Weights and Measures. London.

Petruso, K. 1981. "Early Weights and Weighing in Egypt and the Indus Valley." Bulletin of the Museum of Fine Arts, Boston 79:44-51.

Piccione, P. A. 1980. "In Search of the Meaning of Senet." Archaeology 33,4: 55-58. http://www.jstor.org/stable/41726340.

Stevenson, A. 2009. "Palettes." In UCLA Encyclopedia of Egyptology, edited by W. Wendrich. Los Angeles. https://escholarship.org/uc/item/7dhox2no.

Vogelsang-Eastwood, G. 1999. "Textiles." In Ancient Egyptian Materials and Technology, edited by P. T. Nicholson and I. Shaw, 268-298. Cambridge.

Whitehouse, D. 1997. Roman Glass in the Corning Museum of Glass, Volume One. Corning, NY.

Whitehouse, D. 2004. Roman Glass in the Corning Museum of Glass. Volume Three. Corning, NY. 